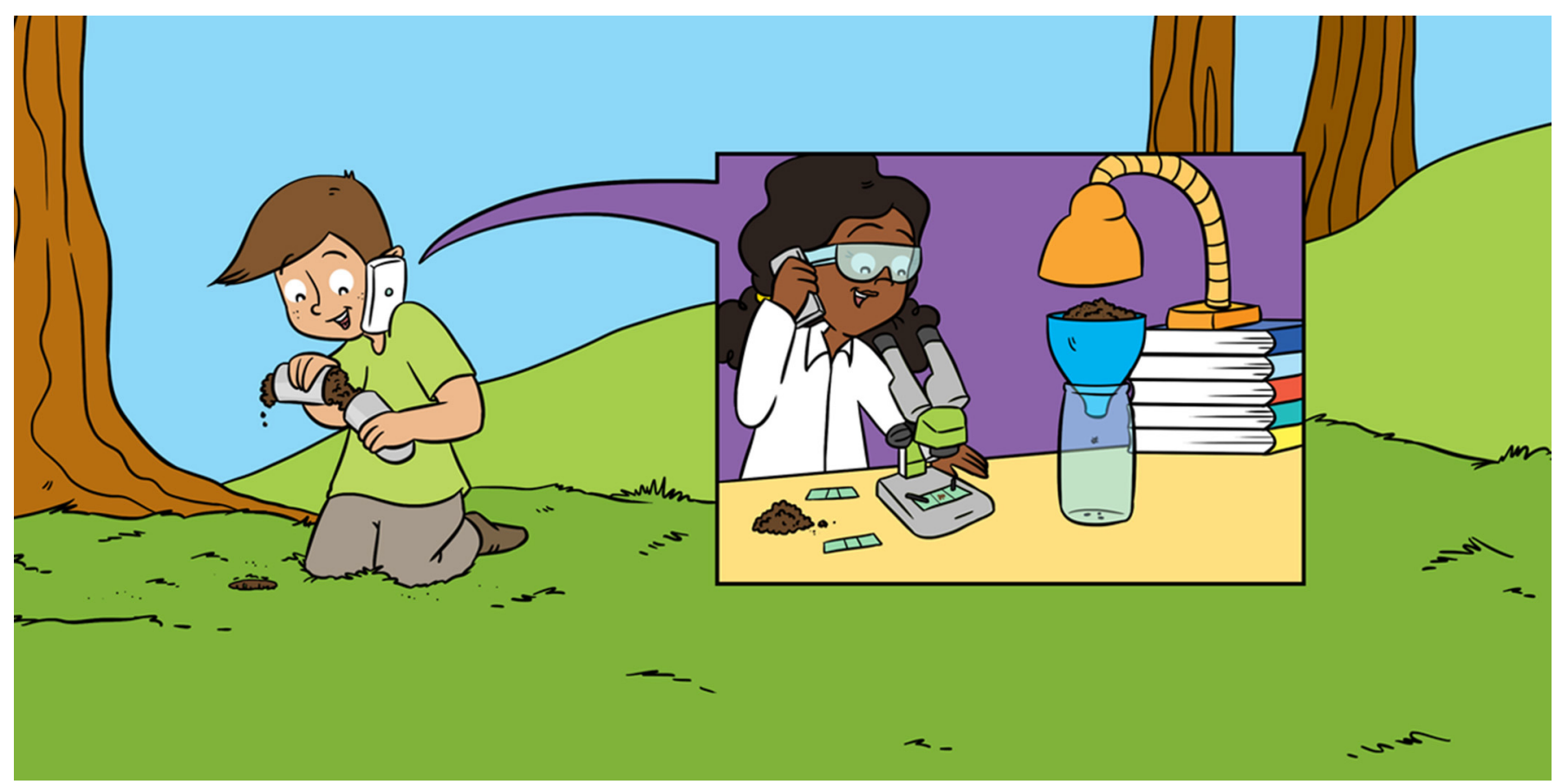

\title{
THE WAY SOIL ORGANISMS LOOK CAN HELP US UNDERSTAND THEIR IMPORTANCE
}

\author{
Pierre Ganault ${ }^{1 *}$, Léa Beaumelle ${ }^{2}$ and Apolline Auclerc ${ }^{3}$ \\ ${ }^{1}$ CEFE, CNRS, EPHE, IRD, Université de Montpellier, Université de Paul-Valéry Montpellier, Montpellier, France \\ 2INRAE, UMR SAVE, Bordeaux, France \\ ${ }^{3}$ Laboratoire Sols et Environnement, Université de Lorraine, INRAE, LSE, Nancy, France
}

YOUNG REVIEWER:

GIULIA

AGE: 13
There is a multitude of life forms on our planet. This is especially true under our feet, in the soil. Earthworms, spiders, and millipedes are only a few examples of the vast number of soil organisms. Once you look what lives in soils, you realize the tremendous diversity of shapes and colors. But what if we take the time to describe all their characteristics: color, size, shape, number of legs, type of wings, lifespan, and climate preferences? All these characteristics, called traits, help us to understand what types of organisms can be found in a particular ecosystem, what they feed on, and how far they can travel. Scientists use this information to understand the different roles of organisms in soils, and to restore degraded soils. Analyzing traits can reveal the importance of soil organisms and the fundamental roles they play for human societies. 
Figure 1

Methods of

sampling and studying soil invertebrates. Small organisms are

extracted from a small soil core by drying the soil and collecting the individuals that fall out of the sample. Large, fast-moving organisms living in leaf litter are collected when they fall into pitfall traps. Less-mobile organisms are extracted from a soil block of soil with a shovel and then sorted by hand. Earthworms living deep in the soil are extracted by pouring a mustard solution into their burrows. Less-mobile organisms living in the leaf litter can be isolated using a Berlese apparatus, which dries the litter and traps the organisms in a jar (Drawing credits: www.lesbullesdemo.fr. Picture credits: Apolline Auclerc, EcoBioDiv lab).

\section{INVERTEBRATE}

A small animals with no internal skeleton, such as insects, worms, or molluscs.

\section{SOIL BIODIVERSITY}

The variety of life forms in soils. It can be measured by the number of species, traits, or genes of these organisms.

\section{SOIL ECOLOGIST}

A scientist investigating soil organisms, their interactions with their environment, and their role in soil functioning

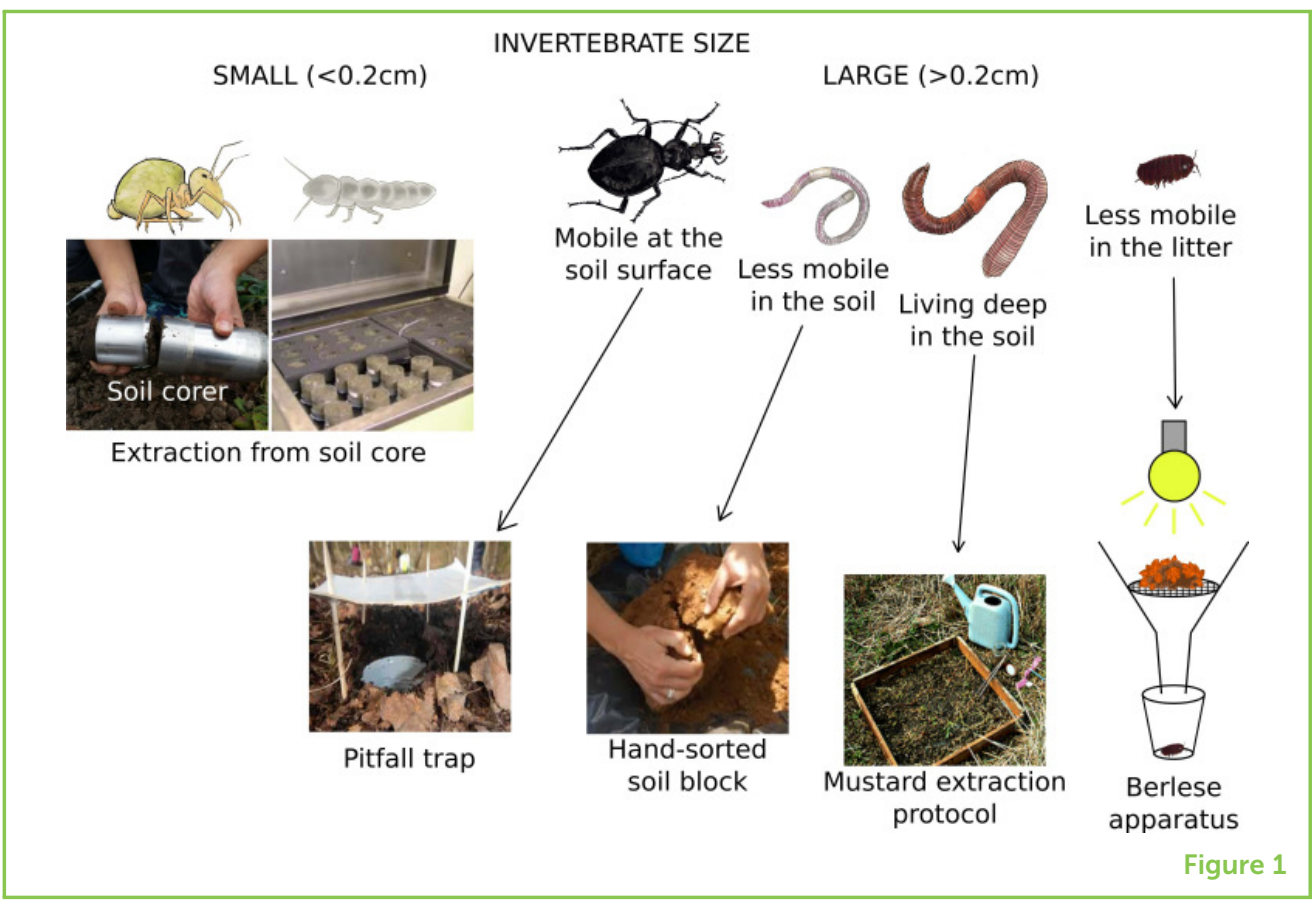

\section{THE SOIL: A WONDERFUL BUT POORLY KNOWN WORLD}

Under our feet, millions of organisms live in the soil [1]. These organisms span from the microscopic (called microorganisms) to invertebrate organisms (such as earthworms) more than 1-m long. The variety of organisms in the soil is called soil biodiversity. Biodiversity means the variations in all the life forms on the planet.

Soil ecologists are scientists who study the diversity of soil organisms. They usually sample the soil organisms living in various places, like tropical rainforests or agricultural fields. They use shovels, traps, or corers to remove soil samples, depending on whether the organisms of interest live within the soil or on its surface (Figure 1). Then, the scientists catch the organisms they can see in their samples by hand or with tweezers. To catch the smallest soil invertebrates, soil ecologists often use a technique called the Berlese method. In the laboratory, they place the soil sample in a funnel, with a heating lamp above the sample and a jar below it. The light and heat make the tiny organisms go down through the funnel into the jar. After a few days, scientist can study the organisms in the jar.

When all the soil organisms are collected, the long and meticulous work starts. Soil scientists count and closely observe each individual organism, to identify which species it belongs to. To do so, they use various types of microscopes along with identification keys and books. The total number of species found in one particular ecosystem represents that ecosystem's biodiversity. Soil scientists have a lot of work to do, because soils are among the most diverse and highly 
Figure 2

Differences in morphological traits between nine species of soil invertebrates belonging to three groups: earthworms, ground beetles, and springtails (Drawing credits:

www.lesbullesdemo.fr)

\section{BERLESE METHOD}

A procedure to extract small-size organism from leaf-litter and soil sample by drying it and collecting organisms that migrate through the sample and fall in a jar.

\section{SPECIES}

Individual organisms that belong to the same species can produce fertile offspring. It is the most commonly used unit to describe life on Earth. All human beings belong to the same species but there are many, many species of soil organisms.

TRAIT

Any characteristic that can be measured on an individual to describe its shape, movement capacity, diet, behavior, or reproduction strategy.

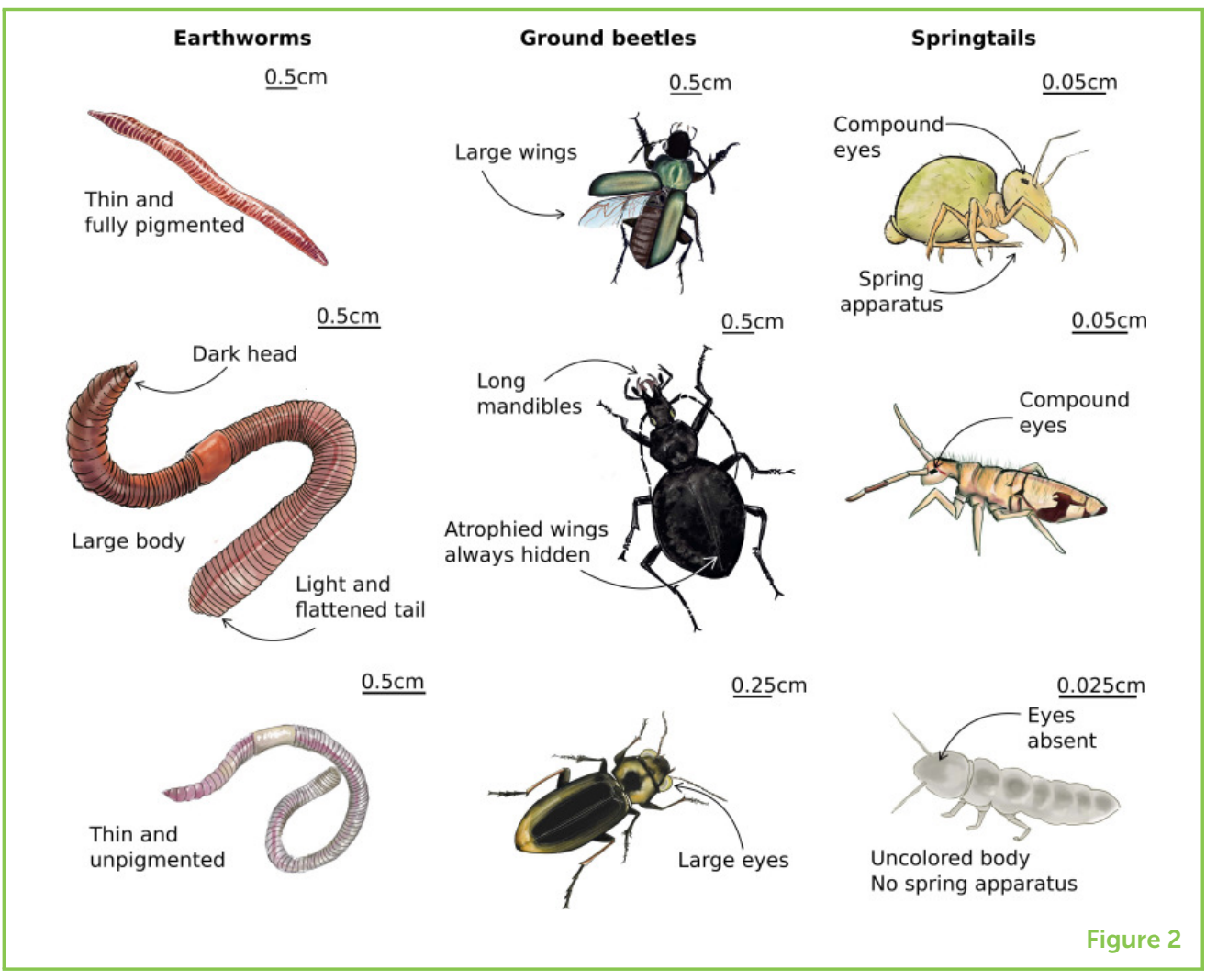

human-impacted ecosystems on Earth. In addition, many soils in the world have not yet been studied, so many species of soil organisms have still not been discovered.

\section{SOIL ORGANISMS ARE EXTREMELY DIVERSE}

Soil biodiversity is so large that it is almost impossible to describe the traits of all soil organisms at once. We will give you an idea of soil diversity by describing the appearance and behaviors of three well-studied types of soil organisms: earthworms, springtails, and ground beetles (Figure 2).

\section{Body Size}

An important structural difference between earthworms, springtails, and ground beetles, and between species within these groups, is their body size. Size is an example of a morphological trait. The smallest earthworm measures several $\mathrm{cm}$ long, while the largest, found in tropical forests, can be $2 \mathrm{~m}$ long. In Europe, ground beetles measure between $2 \mathrm{~mm}$ and $8 \mathrm{~cm}$ from the top of the head to the last segment of the abdomen. Springtails are much smaller, with an average body size of only $2 \mathrm{~mm}$, but their size varies depending on where they live. Some springtail species living in dead leaves are bigger than other species that live deeper in the soil. 


\section{Movement}

To find a habitat with enough food, other organisms with which to reproduce, and a low number of predators, soil organisms have developed numerous techniques for moving, both at the surface and within the soil. Earthworms do not have legs, but some species have strong muscles and small hairs that they use to burrow between soil particles. With their six legs, ground beetles can run on the soil surface to catch their prey. Many species of ground beetles have wings, allowing them to rapidly escape from a predator or other disturbance, or to move to a place where they can find more prey or mates. Springtails also move on their six legs, but thanks to a special appendage that acts like a spring, some springtails can jump several centimeters into the air to escape predators!

\section{Color}

Soil organisms can be colorful. Some earthworms that live in the few first centimeters of soil, in the dead leaves, or in compost or manure are reddish-brown, which enables them to camouflage from their predators against orange-brown dead leaves, but which also protects

\section{UV LIGHT}

Part of the sun's rays that are invisible to the naked eye and can cause sunburn. them from UV light [2]. Other earthworms live deeper in the soil and often have pale colors, such as pale pink, gray, or green. In the dark soil, pigmentation is not necessary because UV light does not penetrate. Still other earthworms live mostly in the soil, but they put their heads out of the soil to feed on dead leaves; consequently, only their heads are pigmented. Springtails show almost the same color patterns as earthworms: pigmented species live on top of the soil and unpigmented ones live within the soil [3]. Finally, ground beetles can have many wonderful color patterns, especially those of the Carabus genus. The vivid colors might discourage their bird predators or might help them to camouflage in their environments.

\section{Mouth Types}

Another stinking difference between our three groups is their mouth type. Ground beetles have strong mandibles (jaws) that can have different shapes and sizes depending on what they eat the most. For example, some species have very long mandibles, projected forward, to reach inside the shells of snails. Springtails have small mouths that allow them to eat fungi growing on leaves and small pieces of the leaves themselves, creating beautiful, skeletonized dead leaves. Earthworms do not have mandibles, but their muscular stomachs are strong enough to crush the soil and the leaves they eat.

\section{THE TRAITS OF SOIL ORGANISMS ARE CLUES TO THEIR IMPORTANT ROLES}

Careful observations of the traits of soil organisms can tell soil ecologists a lot about what the organisms eat, where they live, and how they interact with their environments (Figure 3). The actions of soil 
Figure 3

Soil organisms in action. (1) Earthworm living and feeding on dead leaves. (2)

Earthworm reaching the soil surface through its large, deep burrow. (3) Earthworms living in the soil and digging many burrows. (4) Different springtail species transforming dead leaves into fecal pellets. (5) Springtail escaping from a predator by jumping with its spring-like appendage. (6) Ground beetle feeding on a snail. (7) Ground beetle ready to fly (Drawing credits:

www.lesbullesdemo.fr)

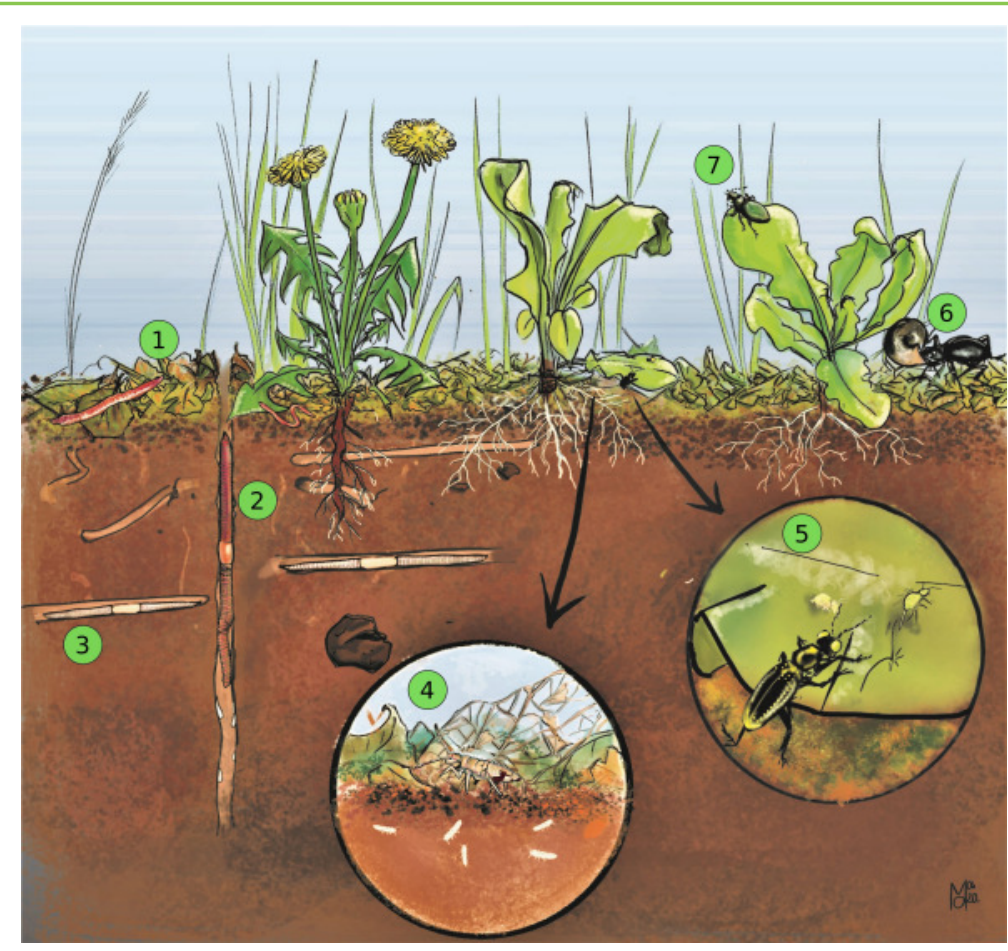

Figure 3

organisms are extremely important for maintaining healthy soils. These organisms can change the physical organization of soil by creating burrows, can add nutrients to the soil through the breakdown of dead leaves, and can help to control the populations of other soil organisms, [4]. Let us look at the important roles played by our three example organisms.

Earthworms play a crucial role in maintaining healthy soils by their intense burrowing activity. The earthworm species that live in the soil move through it, eating the food they find there and mixing the soil particles with pieces of dead leaves. As they move, they create a lot of burrows through which air and water can circulate more easily [5], helping other soil organisms to drink and breathe, and helping plant roots to grow. Some large earthworms create long, wide, vertical burrows (very much like chimneys). Others make thinner burrows, but still contribute strongly to mixing the soil. Earthworms therefore are quite important to reduce flooding and soil erosion, and to improve soil health.

Springtails also play crucial roles in soils, especially by recycling nutrients from dead leaves, which helps with plant growth. In some cases, springtails can reach densities of 10-100,000 individuals per $\mathrm{m}^{2}$ ! They can eat very large amounts of leaf litter and microorganisms (like fungi and bacteria). After eating, they produce many small fecal pellets composed of very tiny pieces of dead leaves mixed with some water. Fecal pellets are the perfect meal for microorganisms, which will continue to transform the dead leaves into nutrients that 
the plants can use. This nutrient recycling performed by springtails and microorganisms is extremely important for ecosystems and plant growth.

Ground beetles have diverse diets, but can be predators feeding on a wide range of prey, from small aphids to larger snails. Ground beetle species are specialized for the prey that they eat; for instance, the species Cychrus caraboides only feeds on snails. Some ground beetles catch tiny springtails, thanks to their well-developed eyes (Figure 3). Ground beetles are important for regulating the populations of other animals. For example, in crops, they feed on the pests that would otherwise damage the crop plants. Farmers can therefore use ground beetles instead of chemicals to fight against pests. This is called biological control, because it uses natural predator-prey interactions between organisms to control pests. It is important to maintain a high diversity of ground beetles in an ecosystem because not all species feed on the same prey. Ground beetles vary in body size and mostly eat prey that is smaller than they are. Therefore, a high diversity of ground beetle species allows a better regulation of pests [6].

Body size, mouth type and size, hunting strategies, and type of prey are important traits that soil ecologists commonly consider to better understand the relationships between soil invertebrates and their environments.

\section{CONCLUSION}

Soil organisms are incredibly diverse in shape and behavior. Soil ecologists explore the wonderful world of the soil and have the chance to discover new species and new traits. By looking at the characteristics of the species they find, soil scientists can better understand the interactions between organisms and ecosystems. Taken together, the numerous roles played by the wide variety of soil organisms are complementary and fundamental to maintaining healthy soils. It is thus very important for us to maintain and conserve soil biodiversity, which is facing the increasing impacts of human activities, such as intensive agriculture and climate change. Raising public awareness of the importance of soil organisms and improving our knowledge of soil biodiversity will be key to decreasing our impacts on the amazing ecosystems under our feet.

\section{ACKNOWLEDGMENTS}

The authors thanks the TEBIS consortium (http://www.reseau-tebis.fr/) and the different NGO, such as Les petits debrouillards (https://www.lespetitsdebrouillards.org) and CARABES (https:// assocarabes.com) with which the authors are working with to increase citizen awareness and encourage protection of soils and 
their biodiversity. The authors also thank Morgane Arietta Ganault for the quality of the detailed drawings, the mentor and young reviewers for their suggestions that improved the manuscript quality, and Susan Debad for her help with English syntax that improved the manuscript clarity.

\section{REFERENCES}

1. Orgiazzi, A., Bardgett, R. D., Barrios, E., Behan-Pelletier, V., Briones, M. J. I., Chotte, J. L., et al. 2016. Global Soil Diversity Atlas. Luxembourg: European Union. Available online at: http://esdac.jrc.ec.europa.eu/public_path/ JRC_global_soilbio_atlas_online.pdf (accessed April 28, 2020).

2. Bottinelli, N., Hedde, M., Jouquet, P., and Capowiez, Y. 2020. An explicit definition of earthworm ecological categories-Marcel Bouché's triangle revisited. Geoderma 372:114361. doi: 10.1016/j.geoderma.2020.114361

3. Potapov, A. A., Semenina, E. E., Korotkevich, A. Yu., Kuznetsova, N. A., and Tiunov, A. V. 2016. Connecting taxonomy and ecology: trophic niches of collembolans as related to taxonomic identity and life forms. Soil Biol. Biochem. 101:20-31. doi: 10.1016/j.soilbio.2016.07.002

4. Pey, B., Nahmani, J., Auclerc, A., Capowiez, Y., Cluzeau, D., Cortet, J., et al. 2014. Current use of and future needs for soil invertebrate functional traits in community ecology. Basic Appl. Ecol. 15:194-206. doi: 10.1016/j.baae.201 4.03.007

5. Capowiez, Y., Bottinelli, N., Sammartino, S., Michel, E., and Jouquet, P. 2015. Morphological and functional characterisation of the burrow systems of six earthworm species (Lumbricidae). Biol. Fertil. Soils 51:869-77. doi: 10.1007/ s00374-015-1036-x

6. Rusch, A., Birkhofer, K., Bommarco, R., Smith, H. G., and Ekbom, B. 2015. Predator body sizes and habitat preferences predict predation rates in an agroecosystem. Basic Appl. Ecology 16:250-9. doi: 10.1016/j.baae.2015.02.003

SUBMITTED: 15 May 2020; ACCEPTED: 12 January 2021;

PUBLISHED ONLINE: 11 February 2021.

EDITED BY: Rémy Beugnon, German Centre for Integrative Biodiversity Research (iDiv), Germany

CITATION: Ganault P, Beaumelle L and Auclerc A (2021) The Way Soil Organisms Look Can Help Us Understand Their Importance. Front. Young Minds 9:562430. doi: $10.3389 /$ frym.2021.562430

CONFLICT OF INTEREST: The authors declare that the research was conducted in the absence of any commercial or financial relationships that could be construed as a potential conflict of interest.

COPYRIGHT @ 2021 Ganault, Beaumelle and Auclerc. This is an open-access article distributed under the terms of the Creative Commons Attribution License (CC BY). The use, distribution or reproduction in other forums is permitted, provided the original author(s) and the copyright owner(s) are credited and that the original 


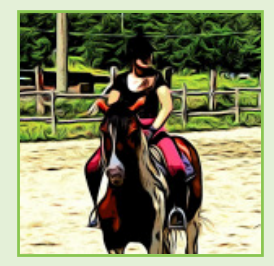

publication in this journal is cited, in accordance with accepted academic practice. No use, distribution or reproduction is permitted which does not comply with these terms.

\section{YOUNG REVIEWER}

\section{GIULIA, AGE: 13}

I am Giulia. I am 13 years old. I like going to school and my favorite subject is English. In my free time, I love playing with my dog, playing tennis, and going to ride horse. In the summer, I like playing in my little swimming pool with my friends and going around my city, all together, by bike. Instead, in the winter, I like very much skiing with my parents and our neighbors.

\section{AUTHORS}

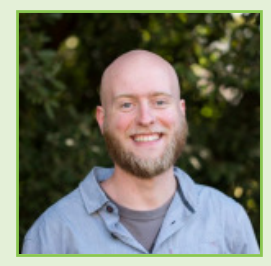

\section{PIERRE GANAULT}

At each walk in nature, I cannot help myself from flipping logs and rocks over or searching into the dead leaves to see what wonderful animal I will find hiding there. This curiosity led me to study soil biodiversity and do a Ph.D. on the response of tree species mixture for soil invertebrates and the role of these animals for soil processes. I also work with associations to bridge the gap between scientist and citizen so we can work all together to study, better understand and protect the creatures living in the soil. *pierre.ganaultagmail.com

\section{LÉA BEAUMELLE}

I am a post-doc at the French National Institute for Agriculture of Bordeaux. My research aims to better understand the impacts of human activities on soil biodiversity and functioning. During my Ph.D. in Versailles, I was studying the response of earthworms to heavy metal pollution. I have expanded my research during my post-docs in France and Germany, by investigating the effects of multiple pollutants, the response of entire soil communities, and the consequences of biodiversity changes for ecosystem processes.

\section{APOLLINE AUCLERC}

I am an Assistant Professor in soil ecology, biology at University of Lorraine in France, Nancy. My research is focused on understanding how the urban and industrial soil ecosystems can host a surprising high level of biodiversity by assessing how invertebrates, such as earthworms, insects, spiders, millipedes... are adapted to the special features of these human-impacted soils. I also develop tools to help citizens to raise their awareness on the soil quality and its unknown biodiversity. 